\title{
Energy efficiency opportunities within the powder coating industry
}

\author{
Sofie Osbeck ${ }^{1}$, Charlotte Bergek ${ }^{1}$, Anders Klässbo ${ }^{1, *}$, Patrik Thollander ${ }^{2}$, Simon Harvey ${ }^{3}$, \\ Patrik Rohdin ${ }^{2}$ \\ ${ }^{1}$ Swerea IVF AB, Mölndal, Sweden \\ ${ }^{2}$ Department of Management and Engineering, Linköping Univeristy, Linköping, Sweden \\ ${ }^{3}$ Department of Energy and Environment, Chalmers University of Technology, Göteborg, Sweden \\ * Corresponding author. Tel: +46 317066073, Fax: +46 31276130, E-mail: anders.klassbo@swerea.se
}

\begin{abstract}
A new challenge to reduce energy usage has emerged in Swedish industry because of increasing energy costs. Energy usage in the Swedish powder coating industry is about 525 GWh annually. This industry has a long and successful record of working towards reduced environmental impact. However, they have not given priority to energy saving investments. Electricity and LPG, for which end-user prices are predicted to increase by as much as $50-60 \%$ by 2020 , are the main energy carriers used in the plants. This paper presents the results of two detailed industrial energy audits conducted with the aim of quantifying the energy efficiency potential for the Swedish powder coating industry. Energy auditing and pinch analysis methods were used to identify possible energy housekeeping measures and heat exchanging opportunities. The biggest users of energy within the plants are the cure oven, drying oven and pre-treatment units. The energy use reduction by the housekeeping measures is $8-19 \%$ and by thermal heat recovery an additional $8-13 \%$. These measures result in an average energy cost saving of $25 \%$ and reduction of carbon dioxide emissions of $30 \%$. The results indicate that the powder coating industry has a total energy efficiency potential of at least $20 \%$.
\end{abstract}

Keywords: Powder coating, energy audit, pinch analysis, energy efficiency

\section{Introduction}

The Swedish electricity market was liberalized 1996 in order to increase competition. The European electricity market deregulation was delayed until 2004 before it was liberalized for industrial consumers, which has led to increased electricity prices in Sweden [1]. Industry accounts for $40 \%$ of Sweden's total energy use, which is forecasted to increase due to greater industrial demand. Hopefully new eco-efficient technology as well as increased energy efficiency will reduce the rate of increase of energy usage in industry [2].

The 20-20-20-targets have been formulated by the EU commission in order to achieve their energy policy vision: competitiveness, sustainability and security-of supply. The targets represent 20\% reduction in energy use and at least 20\% share of renewable energy supply based on the 2005-levels and a 20\% reduction in greenhouse gas emissions based on the 1990-level. Key areas of the EU targets are in the electricity and gas markets, renewable energy sources, consumer behavior and closer international cooperation. All EU countries are encouraged to act and coordinate activities in order to try to distribute the burden but also its future dividends. Policy instruments have been introduced in Sweden to achieve these goals and guide the energy use in a sustainable direction, and decrease emissions to reduce climate change. The instruments include energy, carbon and sulfur taxes but also the electricity certificate system, program for Energy Efficiency (PFE), the energy audit program, technology procurement, policy instruments for buildings and transport and information [3]. The end user prices of electricity and liquefied petroleum gas (LPG) is predicted to increase by as much as $50-60 \%$ by 2020 [4]. This is another driving force in implementing energy efficiency measures. Beside the environmental and economical benefits from making industrial energy usage more efficient there are also marketing benefits as customers begin to require energy-efficient production within the powder coating industry [5]. 
Experience from Swedish research in industry reveals that the energy saving potential among non energy-intensive companies ranges from 15-50\% [6-7]. No figures are available for the energy saving potential in the energy-intensive powder coating industry. The aim of this paper is to quantify energy efficiency potential for the Swedish powder coating industry based on two thorough industrial energy audits. The research was conducted using multiple case study analysis, energy audit as well as pinch analysis.

The Swedish powder coating industry includes approximately 350 plants using more than one metric ton of coating powder. These currently accounts for a combined energy usage of 525 $\mathrm{GWh} /$ year, corresponding to $1,5 \mathrm{GWh} /$ year per plant [5]. This sector has successfully implemented eco-technology as a result of legal requirements. However, so far they have not given priority to energy saving investments. A powder coating plant usually includes pretreatment, drying oven, powder box and cure oven, e.g. see Fig. 6. In the pre-treatment unit, the parts that are to be coated are washed in a degreasing step with alkaline washing solution of around $60^{\circ} \mathrm{C}$. The pre-treatment also includes a number of rinsing steps. The parts go through a drying oven that has a temperature of around $120-150^{\circ} \mathrm{C}$. Then one layer of powder is applied in the powder box and at the end of the conveyor the parts go through a cure oven that has a temperature of $200^{\circ} \mathrm{C}$. After the cure oven some plants have a cooling zone where cold air is blown over the parts to make them cool faster [8].

Two companies were selected for this multiple case study analysis [5]. Company A uses LPG as fuel for firing an immersed heater in order to heat their first pre-treatment bath. Company B uses district heating instead. Direct burners using LPG heat the drying ovens to a temperature of $150^{\circ} \mathrm{C}$ and $120^{\circ} \mathrm{C}$ respectively. The cure oven is heated by electricity to $200^{\circ} \mathrm{C}$ at Company A while Company B uses LPG with direct burners. Company B also has a primer box, primer oven and cooling zone while Company A has a liquid finish box between the drying oven and the powder box. All components besides heating accessories are driven by electricity.

\section{Methodology}

The electricity use is based on instantaneous measurements for the different units of the process as well as on logging of selected components and it was performed during one week for each company. The values from the logging were used to evaluate how many hours the different parts of the process are in use each day as well as to get an average value for the electricity usage. The calculated energy use of electricity was compared with the electricity invoices. This comparison made it possible to extrapolate the logged and instantaneous measurements to the usage of one year. The usage of district heating and LPG was based on the monthly values for the consumption stated on the invoices. Invoices for one year were compared for all three energy carriers.

Pinch analysis is a tool to analyse industrial process systems and determine how much heat that must be added, how much excess heat must be removed and how much heat that can be recovered within the process. Pinch technology is also a useful tool to investigate how to design a heat exchanger network in order to achieve maximum heat recovery. In this project the heat content in the different streams was estimated based on process data and after this different possible options for heat exchange were investigated. The heat usage depends on the different production schemes, when the processes are used, for how long and the distance between them. In the end the options are weighed against each other based on energy cost savings and capital investment required.

The payoff period and the net present value (NPV) method were used to evaluate the investments. The payoff period quantifies the time period necessary for the investment's 
energy cost savings to cover the initial investment cost. The net present value method evaluates the viability of an initial investment by comparing it with all future energy related cash flows. All future cash flows are discounted using the interest rate and a reference period of time. The net present value ratio (NPV divided by initial investment) is used to compare different investments. The investment with the maximum ratio is the most attractive. In the base case, the investments are analyzed assuming constant energy prices over the lifetime of the investment. In a sensitivity analysis, the analysis accounts for the development of energy prices during the years $2010-2020$.

\section{Results}

The energy audit showed that $77-86 \%$ of total energy usage occurs in the core production processes, whereas $14-23 \%$ is connected to the support processes. The first graphs illustrate the electricity use during an average production day. As can be seen in Fig. 1a, company A has two peaks for the production processes during the day. This is because they operate with two shifts and they have a large variation of products. Company B, e.g. Fig. 1b, has a more homogeneous production and single-shift operation. Significant differences can be seen when analysing how the electrical power load is distributed between the process units during operating hours, e.g. Fig. 2. For Company A the cure oven is the largest consumer of electricity and for Company B it is the powder box. For Company A the cure oven can be used at three different temperatures due to combination of liquid finishing and powder coating. The powder box in Company $\mathrm{B}$ has a high ventilation requirement because of a more open construction and employees working inside compared to Company A. Figures 1 and 2 are comparable when production is at its full capacity.
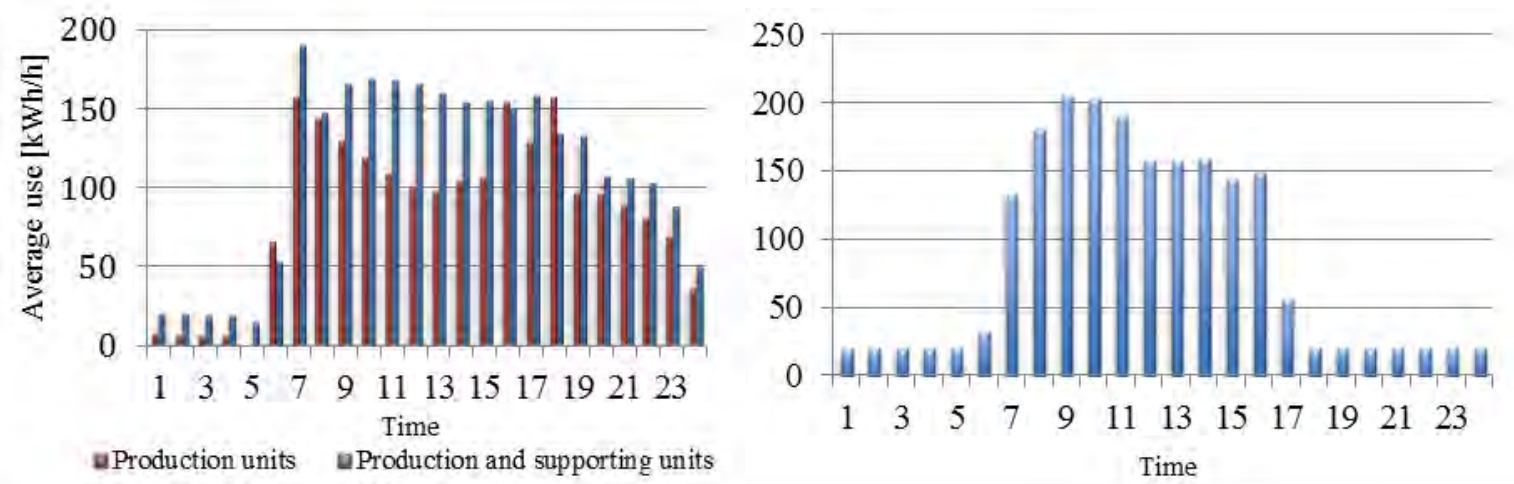

Fig. 1. Electricity use during an average production day for Company A (left) and B (right).
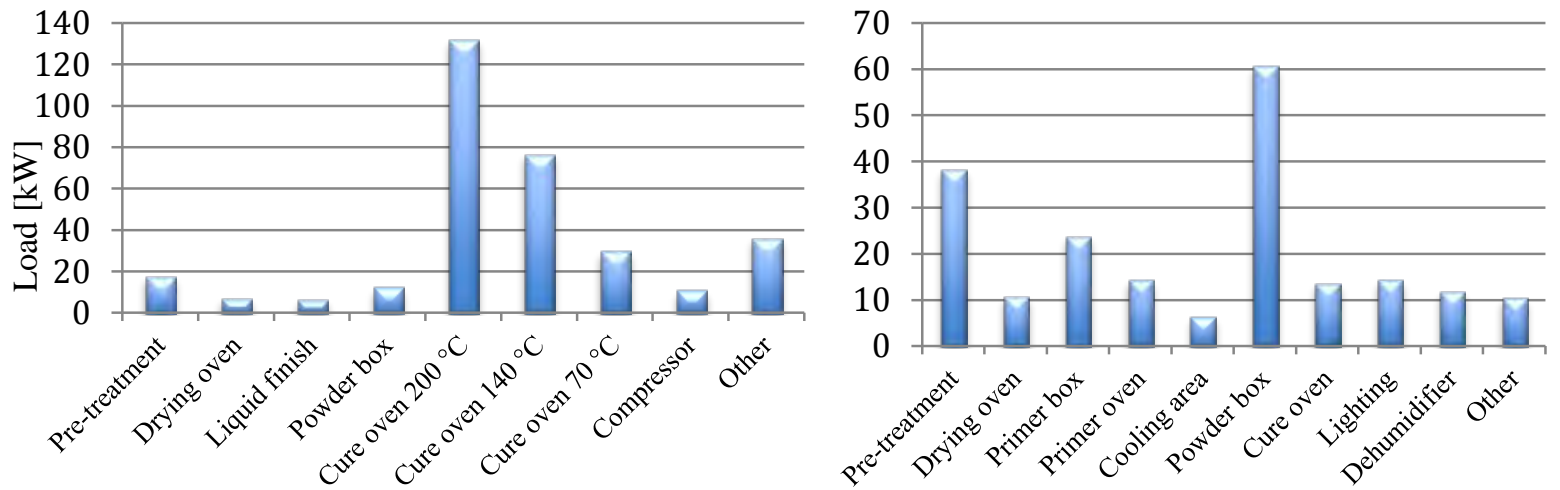

Fig. 2. Load balance for electricity during production for Company A (left) and B (right).

In the energy balance all energy sources are included, i.e. electricity and LPG for Company A and electricity, LPG and district heating for Company B, e.g. Fig. 3. As can be seen it is the pre-treatment, drying oven and cure oven that uses most energy. Together these three units 
accounts for about $70 \%$ of the total energy supply for both companies. When using liquid finishing (65\% of the time) the pre-treatment and drying oven are turned off for company A, which leads to a lower demand for LPG for this company. For company B it is the primer box, primer oven and cooling zone that can be turned off during periods.
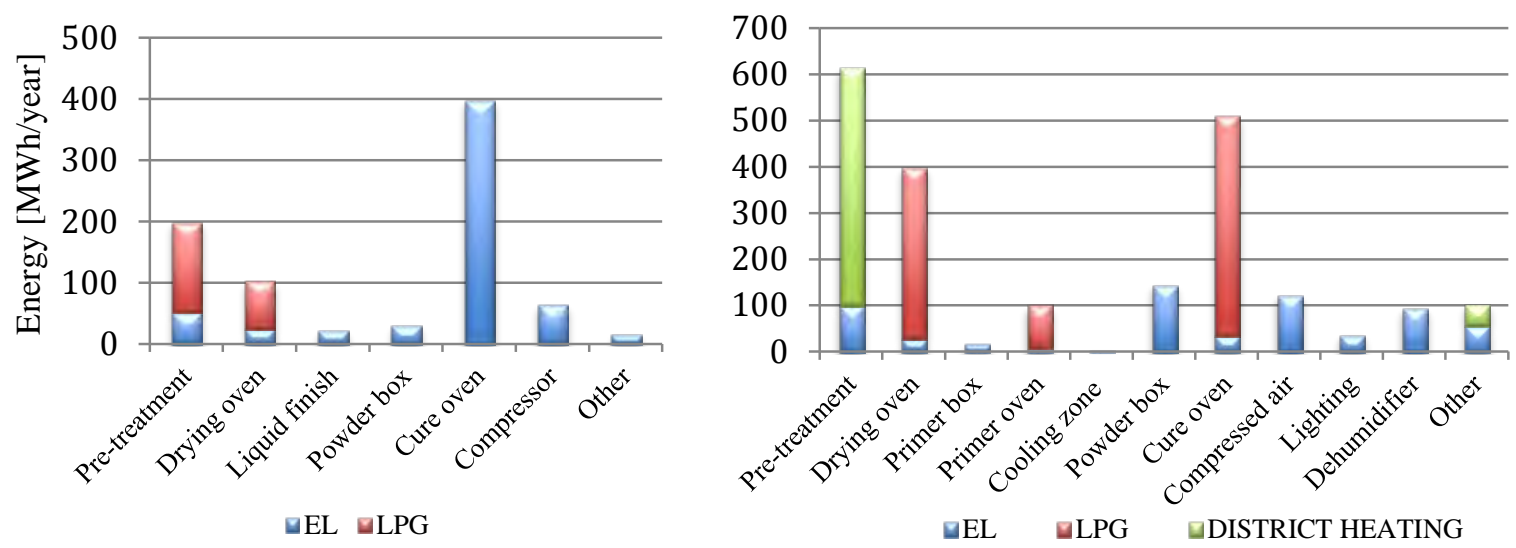

Fig. 3. Energy balance during one year for Company A (left) and B (right).

Figure 4 shows the total energy use for the two companies. Both companies have a significant use of electricity during downtime. This is due to that both have dehumidifiers that are on all the time as well as charging of trucks during the nights.
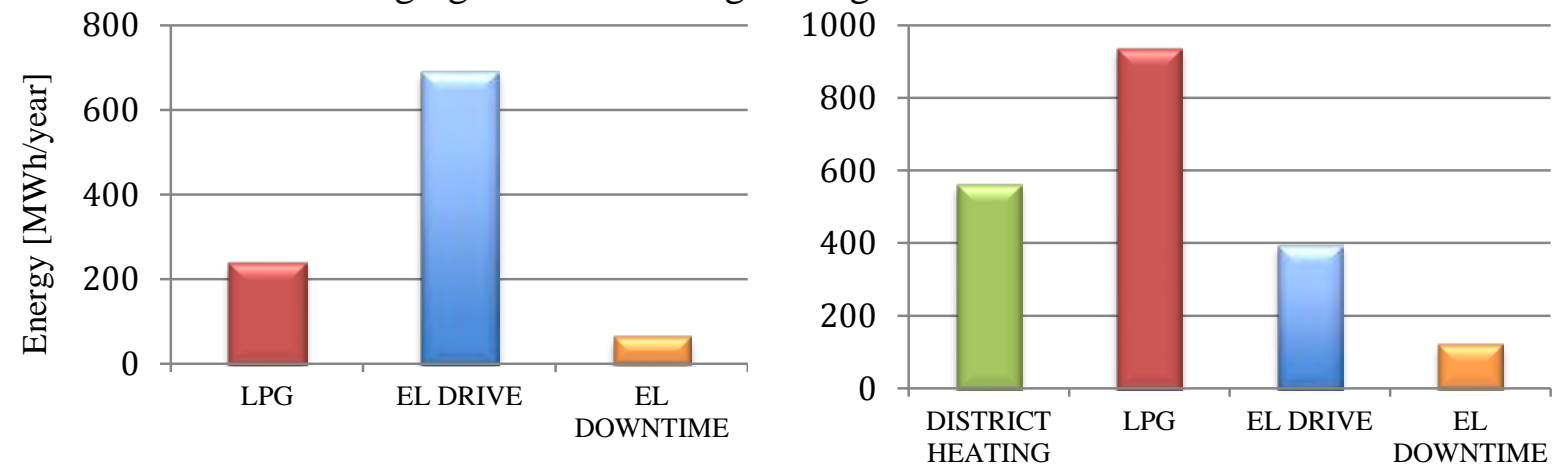

Fig. 4. Total energy use per year for Company A (left) and B (right).
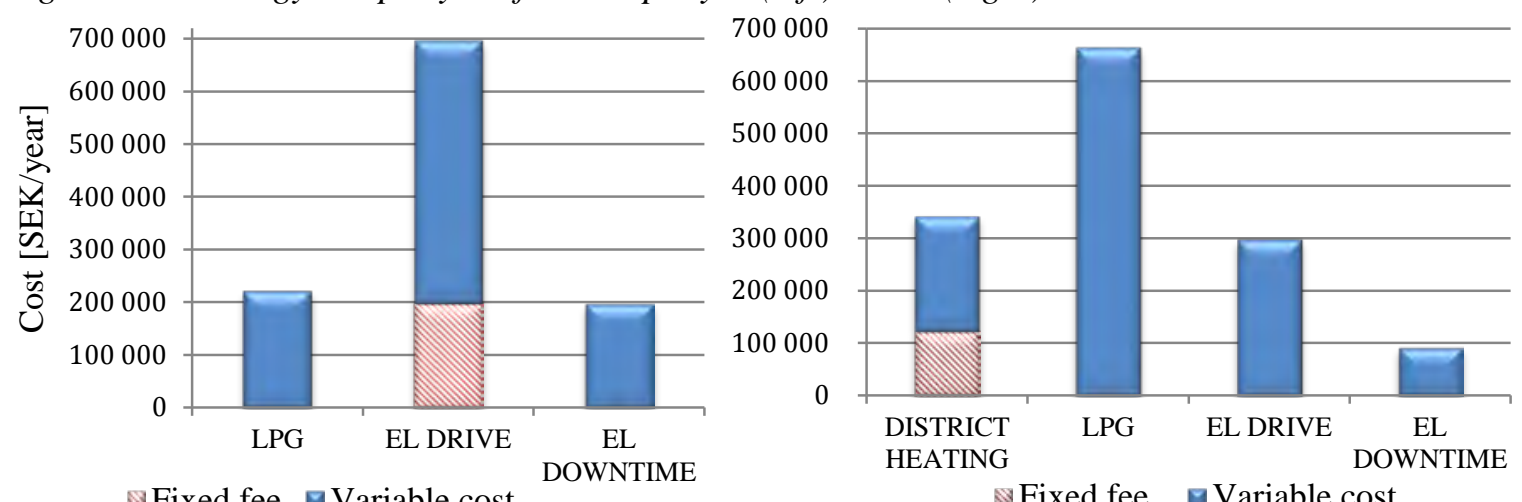

Fig. 5. Energy cost per year for Company A (left) and B (right).

The energy cost can be seen in Figure 5 above. Company A has a fixed fee for electricity but not for LPG. Company B has a fixed fee for district heating but not for the other energy sources. Electricity is the highest energy cost for company A while LPG is the highest cost for company B.

The specific energy usage indicators have been chosen based on a national project within Swedish industry named ENIG (EN in Groups), see Table 1. One main difference between the two companies is that Company A uses half as much energy per year but has twice as much 
production time. This is because Company A combines other varnishing techniques and offers packing and masking. Company B only uses powder coating technology which is more energy demanding. Since the turnover is similar the second indicator depends mostly on the energy use. The mass flow of parts is more than twice as high for Company B compared to Company A, which affects the third indicator (specific energy usage per ton of product).

Table 1. Specific energy usage indicators.

\begin{tabular}{llll}
\hline Company & Energy use per & & \\
\hline & Production time & Turnover & Parts \\
& {$[\mathrm{kWh} / \mathrm{h}]$} & {$[\mathrm{kWh} / \mathrm{kSEK}]$} & {$[\mathrm{kWh} / \mathrm{Ton}]$} \\
\hline Company A & 230 & 47 & 185 \\
Company B & 973 & 107 & 135 \\
\hline
\end{tabular}

The reduction of $\mathrm{CO}_{2}$-emissions for the suggested measures are based on values of $234 \mathrm{~kg}$ $\mathrm{CO}_{2} / \mathrm{MWh}$ of LPG, $770 \mathrm{~kg} \mathrm{CO} / \mathrm{MWh}$ of electricity and $0 \mathrm{~kg} \mathrm{CO} / \mathrm{MWh}$ for district heating. Electricity has a high value due to that it is assumed to be electricity on the margin and district heating has zero emissions due to production from biomass. The energy prices can be seen in Table 2. The prices for 2010 is stated on the companies invoices and the increase until 2020 is expected to be $60 \%$ for LPG, $50 \%$ for electricity and $30 \%$ for biomass [4].

Table 2. Energy prices for 2010 and 2020.

\begin{tabular}{lllllll}
\hline Company & \multicolumn{6}{l}{ Energy price [SEK/MWh] } \\
\hline & El. 2010 & El. 2020 & LPG 2010 & LPG 2020 & DH 2010 & DH 2020 \\
\hline Company A & 735 & 1103 & 953 & 1525 & & \\
Company B & 755 & 1133 & 707 & 1131 & 391 & 508 \\
\hline
\end{tabular}

Energy housekeeping measures do not include heat exchanging and are primarily targeted at identifying better operational practices. The potential energy usage reduction, based on such measures was estimated at $8-19 \%$, e.g. Table 3.

Table 3. Energy housekeeping measures (compared with the total energy use for each company).

\begin{tabular}{llll}
\hline Measure & \multicolumn{2}{l}{ Reduction potential } & \\
\hline Company A & $\begin{array}{l}\text { Energy } \\
\text { [MWh/year] }\end{array}$ & $\begin{array}{l}\text { Running cost } \\
\text { [SEK/year] }\end{array}$ & $\begin{array}{l}\mathrm{CO}_{2} \text {-emission } \\
\text { [Ton/year] }\end{array}$ \\
\hline Lighting & 22 & 17000 & 17 \\
Standby & 65 & 49000 & 50 \\
Production planning & 100 & 74000 & 77 \\
Drying oven & 8 & 6000 & 2 \\
Total & $195(19 \%)$ & $147000(15 \%)$ & $146(23 \%)$ \\
\hline Company B & & & 14 \\
\hline Lighting & 18 & 14000 & 24 \\
Dehumidifier & 31 & 24000 & 10 \\
Powder box's ventilation & 13 & 10000 & 34 \\
Production planning & 44 & 33000 & 13 \\
Fans & 16 & 12000 & 34 \\
New powder box & 44 & 33000 & $129(26 \%)$ \\
Total & $166(8 \%)$ & $176000(9 \%)$ & \\
\hline
\end{tabular}

Lighting measures include switching to low energy lighting, removing it in areas where it is not necessary as well as turning off when not in use. Both companies have several 
applications on standby during nights and weekends, for example compressor and dehumidifier. Complete shut-off of such equipment can lead to substantial energy savings. Company B can turn off the powder box ventilation during breaks. Production planning could reduce the energy usage by having one start per day and process unit. Using a lower temperature in the drying oven for Company A could decrease energy usage but it also generates a risk of lower coating quality. The fans to the drying oven and cure oven are oversized for Company B and changing them could reduce the plant's power load. If Best Available Technology (BAT) is adopted for the powder box, electricity use for the ventilation within the box could be reduced by $30 \%$ and the compressed air usage by $45 \%$.

Pinch analysis was used to identify opportunities for heat recovery by heat exchanging. Two possible heat recovery cases were investigated, e.g. Table 4. Case 1 involves heat exchanging incoming and outgoing airflows in the cure oven and drying oven, e.g. Fig. 6.

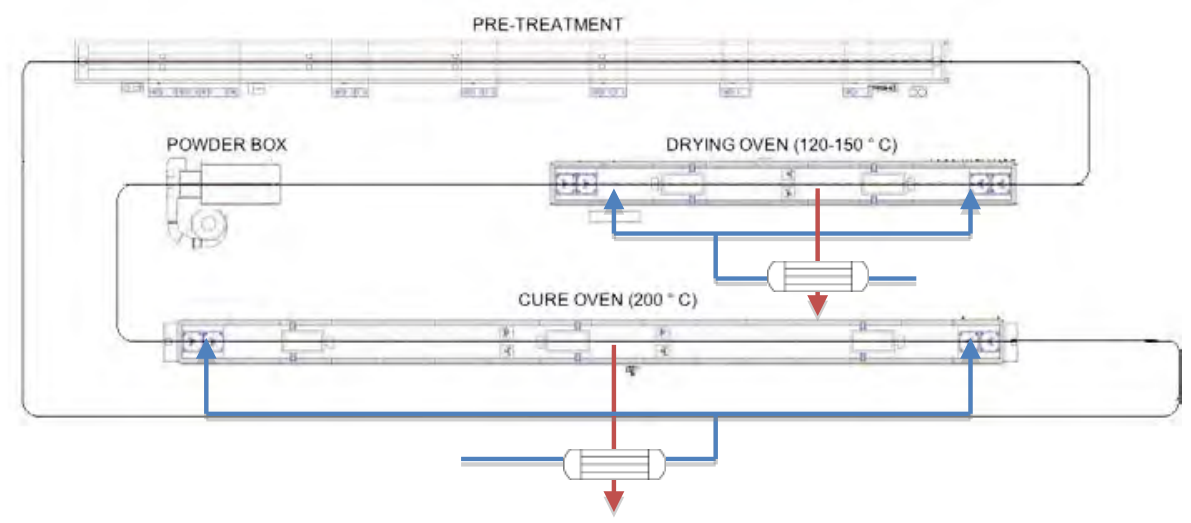

Fig. 6. Case 1 Proposed heat exchanging measures for powder coating process.

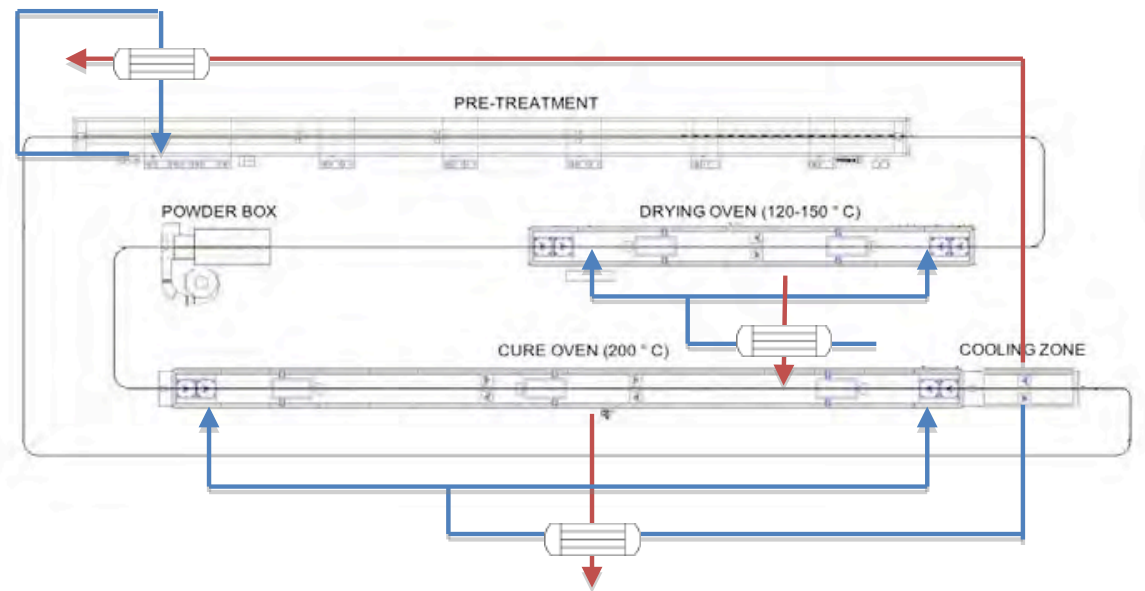

Fig. 7. Case 2 Proposed heat exchanging measures for powder coating process.

Table 4. Saving potentials for heat recovery cases.

\begin{tabular}{llll}
\hline Measure & Reduction potential & & \\
\hline & Energy & Running cost & $\mathrm{CO}_{2}$-emission \\
[MWh/year] & [SEK/year] & 76 \\
\hline Case 1 Company A & 121 & 90000 & 73 \\
Case 2 Company A & 128 & 85000 & 33 \\
\hline Case 1 Company B & 140 & 100000 & 28 \\
Case 2 Company B & 251 & 146000 & \\
\hline
\end{tabular}


Case 2 includes a cooling zone after the cure oven. The large airflow from the cooling zone can be divided and used as preheated ingoing air to the cure oven as well as for heat exchanging to heat the pre-treatment bath. For the drying oven the heat exchange is the same as in Case 1, e.g. Fig. 7.

The economic assessment, e.g. Table 5, shows that the two cases for heat recovery are profitable for both companies. However, Case 1 has a much higher NPV and NPVR than Case 2. The total savings are presented in Table 6, showing that Company A has a higher potential for reduction of energy use due to more variations in the production as well as larger hot streams out from the ovens.

Table 5. Economic assessment with expected increased energy prices until 2020 for Company A (interest rate 10\%) and Company B (interest rate 15\%).

\begin{tabular}{lllll}
\hline Measure & & & \\
\hline Period 10 years & $\begin{array}{l}\text { Investment cost } \\
\text { [SEK] }\end{array}$ & $\begin{array}{l}\text { Pay off period } \\
\text { [year] }\end{array}$ & $\begin{array}{l}\text { NPV } \\
\text { [SEK] }\end{array}$ & NPVR \\
\hline Case 1 Company A & 135000 & 0,9 & 795000 & 5,90 \\
Case 2 Company A & 450000 & 3,1 & 440000 & 1,00 \\
\hline Case 1 Company B & 150000 & 1,2 & 460000 & 3,08 \\
Case 2 Company B & 495000 & 2,8 & 400000 & 0,80 \\
\hline
\end{tabular}

Table 6. Total savings for energy housekeeping measures plus thermal heat recovery cases (compared with the total energy use).

\begin{tabular}{llll}
\hline Measure & Reduction potential & & \\
\hline & $\begin{array}{l}\text { Energy } \\
\text { [MWh/year] }\end{array}$ & $\begin{array}{l}\text { Running cost } \\
\text { [SEK/year] }\end{array}$ & $\begin{array}{l}\mathrm{CO}_{2} \text {-emission } \\
\text { [Ton/year] }\end{array}$ \\
\hline EHK+Case 1 Company A & $316(32 \%)$ & $237000(26 \%)$ & $220(35 \%)$ \\
EHK+Case 2 Company A & $323(33 \%)$ & $232000(25 \%)$ & $219(34 \%)$ \\
\hline EHK+Case 1 Company B & $306(16 \%)$ & $276000(20 \%)$ & $162(26 \%)$ \\
EHK+Case 2 Company B & $417(21 \%)$ & $322000(23 \%)$ & $157(25 \%)$ \\
\hline
\end{tabular}

\section{Concluding discussion}

The energy audit shows that the production processes use a substantial amount of energy 77 $86 \%$ whereas the support processes use $14-23 \%$. For the two companies investigated the energy usage can be reduced by $8-19 \%$ with energy housekeeping measures. Thermal heat exchange can reduce the energy use by an additional $8-13 \%$. In total this gives energy savings of around $30 \%$ for company A and $20 \%$ for company B.

Improved production planning will make a large impact on energy usage. For company A this could lead to a reduction of the second electricity use peak, e.g. Fig. 1a. For company B turning on the primer part only once a day could save energy. Another measure for company A is to completely turn off equipment that is not used. For company B the powder box can be turned off during breaks. These are measures that can be implemented by changing the routines etc. within the companies. In this study, energy housekeeping measures have been shown to achieve the same or higher energy savings compared to thermal heat recovery.

Benchmarking shows that the most efficient way of heat exchanging is within the same part in the process. This will reduce the investment costs as well as contribute to a flexible process. Installing a cooling zone after the cure oven will be profitable but there are other investments 
that are even more profitable. The fact that the cooling zone will give a better working environment should be taken into account. The benchmarking also shows that the airlocks from the ovens usually have too small heat content to be efficiently heat exchanged against ingoing air to the ovens. The contaminations that follow the airlocks also prevent using this air as ingoing air. Another reason is that there is a risk that to much air is pushed into the ovens if airlocks are used. However, there might be a possibility to use them for heat exchanging against facility ventilation air to reduce demand for space heating. To be able to implement thermal heat exchange further study is necessary in order to investigate the impact of contaminants released from the powders when cured in the cure oven. There is a possibility that these contaminants will stick in the heat exchangers and tests must be conducted to see if filters are required upstream from the heat exchangers. It should be noted that companies in Finland have successfully used the airlocks for space heating [5].

The economic results are based on an interest rate of $10 \%$ and $15 \%$ respectively. A lower interest rate would increase the net present value and the net present value ratio. The results in these projects show that Case 1 is the best investments from an economical perspective for both companies. However, Case 2 has other positive effects that are not accounted for in the calculations. For example a cooling zone would substantially improve the working environment by reducing the heat that is emitted to the facility. Results indicate, based on benchmarking between these two projects, that the powder coating industry may have an energy efficiency potential of $20 \%$ which corresponds to total energy savings of at least 105 $\mathrm{GWh} /$ year for the sector.

\section{References}

[1] B. Karlsson, Strategi för systemförändringar av industriell energianvändning, Linköpings universitet, 2001-05-02, pp 1-3.

[2] T. Kåberger, D. Andersson, Energiförsörjningen I Sverige - en korttidsprognos, Energimyndigheten, ISSN 1403-1892, 2009, pp 17-20.

[3] T. Kåberger, S. Lublin, A. Andersson, Energiläget 2009, Energimyndigheten, pp 8-12, 31

[4] Simon Harvey, Department of Energy and Environment, Chalmers University of Technology, 2010.

[5] Lars Österberg, Svensk Pulverlackteknisk Förening, 2010.

[6] Trygg, L., Karlsson B., 2005. Industrial DSM in a deregulated European electricity market - a case study of 11 plants in Sweden. Energy Policy 33 (11): 1445-1459.

[7] Thollander, P., Rohdin, P., Danestig, M., 2007. Energy policies for increased industrial energy efficiency: Evaluation of a local energy programme for manufacturing SMEs. Energy Policy;35(11):5774-83.

[8] Liberto, N., 2003. Users's guide to Powder Coating $4^{\text {th }}$ edition,. 